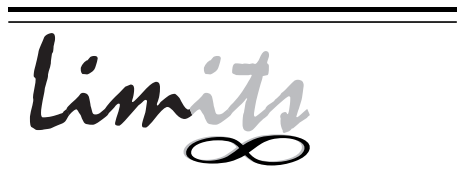

J. Math. and Its Appl.

ISSN : $1829-605 \mathrm{X}$

Vol. 6, No. 1, May 2009, 1-9

\title{
KAJIAN ANALISIS DALAM METODE ASIMILASI DATA
}

\author{
Erna Apriliani \\ Jurusan Matematika, FMIPA ITS Surabaya \\ april@matematika.its.ac.id
}

\begin{abstract}
Abstrak
Asimilasi data adalah suatu metode estimasi yang diperoleh dari penggabungan antara model sistem dan data-data pengukuran. Salah satu metode asimilasi data adalah Kalman filter yang merupakan metode estimasi variabel keadaan dari sistem dinamik stokastik. Filter Kalman telah banyak diterapkan pada berbagai bidang ilmu antara lain hidrodinamika, meteorologi, navigasi pesawat dan masalah matematika finansial. Algoritma dasar dari Filter Kalman telah banyak mengalami perkembangan agar dapat diterapkan pada masalah real dan mempunyai waktu komputasi yang cepat. Pada makalah ini akan disajikan beberapa contoh pengembangan algoritma filter Kalman atau asimilasi data secara umum yang memerlukan kajian analisis. Aspek-aspek analisis yang sering diperlukan antara lain norm matriks, konvergensi dan kestabilan. Katakunci: reduksi rank, dekomposisi nilai singular, sistem persamaan linear
\end{abstract}

\section{Pendahuluan}

Asimilasi data adalah suatu metode estimasi yang diperoleh dari penggabungan antara model sistem dan data-data pengukuran. Salah satu metode 
asimilasi data adalah Filter Kalman. Filter Kalman merupakan metode estimasi variabel keadaan dari sistem dinamik stokastik. Filter Kalman telah banyak diterapkan pada berbagai bidang ilmu antara lain hidrodinamika, meteorologi, navigasi pesawat, dan masalah matematika finansial. Algoritma dasar dari Filter Kalman telah banyak mengalami perkembangan agar dapat diterapkan pada masalah real dan mempunyai waktu komputasi yang cepat.

Tujuan dari pengembangan atau modifikasi dari algoritma adalah untuk memudahkan perhitungan, mengurangi waktu komputasi serta memperkecil kesalahan eatimasi. Algoritma pengembangan yang telah diperoleh harus dikaji konvergensinya artinya hasil estimasi yang diperoleh mendekati hasil estimasi filter Kalman dasar serta kestabilan algoritma harus terjamin. Oleh karena itu diperlukan kajian secara analisis apakah konvergensi dan kestab ilan algoritma tersebut terpenuhi, sebelum menerapkan algoritma tersebut pada suatu kasus tertentu.

Pada makalah ini akan disajikan beberapa kajian pengembangan algoritma filter Kalman yang telah dilakukan penulis dan peneliti lainnya yang memerlukan kemampuan analisis. Dari tulisan ini diharapkan memperkuat keyakinan bahwa kita tidak dapat mengembangkan suatu ilmu, algoritma ataupun metode tanpa kemampuan analisis yang cukup. Aspek-aspek analisis yang sering dipergunakan disini antara lain norm suatu matriks, konvergensi dan kestabilan.

\section{Asimilasi Data}

Asimilasi data adalah metode estimasi variabel dan parameter yang merupakan gabungan antara model dinamik sistem dan data-data pengukuran. Disini akan diberikan contoh bagaimana peranan analisis dalam asimilasi data. Le Dimet FX [3] dalam papernya yang berjudul The problem of $d a-$ ta assimilation for soil water movement, memberikan model matematika dari gerakan air secara horisontal berupa persamaan parabolic quasilinear sebagai berikut:

$$
\frac{\partial \theta}{\partial t}=\frac{\partial}{\partial z}\left(D(\theta) \frac{\partial \theta}{\partial z}\right)-\frac{\partial K(\theta)}{\partial z}
$$

dengan koefisien nonlinear 


$$
\begin{aligned}
D(\theta) & =\frac{-b \phi_{s} K_{s}}{\theta_{s}}\left(\frac{\theta}{\theta_{s}}\right)^{b+2} \\
K(\theta) & =K_{s}\left(\frac{\theta}{\theta_{s}}\right)^{2 b+3}
\end{aligned}
$$

Dalam paper tersebut dikaji tentang keujudan dan ketunggalan penyelesaian persamaan parabolic quasilinear tersebut dengan syarat batas yang tak linear.

Untuk menyelesesaikan masalah tersebut dilakukan transformasi Kirchoff

$$
u=\int_{0}^{\theta} D(s) d s
$$

diasumsikan $K(\theta)$ terdeferensial hampir dimana-mana dan $\left|\frac{\partial K}{\partial u}\right| \leq$ $k_{2}, k_{2}$ konstan. Pada kasus ini juga diperlukan fungsi yang terintegral Lebesgue kuadrat, ruang Sobolev operator terbatas serta bagaimana keberadaan solusi lemah dan solusi kuat. Selain itu juga dibahas operator linear $A: Y \rightarrow Y$ dengan domain $D(A)=Y_{1}$ yang didefinisikan dengan

$$
A \varphi=-\alpha \frac{\partial^{2} \varphi}{\partial z^{2}} ; \varphi \in Y_{1}
$$

didefinisiskan norm di $W_{T}$ sebagai berikut

$$
\|w\|_{W_{T}}=\left\|-\frac{d w}{d t}+A^{*} w\right\|_{Y}
$$

dengan operator $A^{*}: Y \rightarrow Y$ adalah adjoint $A$. Pada kondisi $A^{*}$ identik dengan $A$ berarti $\left.L_{2}(0, T ; X)\right)^{*} \equiv L_{2}(0, T ; X)$

Tampak dalam paper tersebut banyak kerterkaitan antara asimilasi data dengan analisis real maupun analisis fungsional antara lain: terdeferensial hampir dimana-mana, terintegral Lebesgue, ruang Sobolev, operator terbatas, norm, sifat identik suatu operator dan lain-lain.

Dalam bab-bab berikut merupakan perjalanan penelitian yang berkaitan dengan filter Kalman. 


\section{Filter Kalman dan Pengembangan Algoritmanya}

Pada bab ini akan ditunjukkan pemakaian analisis dalam menganalisa keterbatasan matriks kovariansi, kestabilan filter Kalman dan konvergensi dari algoritma pengembangannya.

Misalkan diberikan sistem dinamik stokastik waktu diskrit

$$
x_{k+1}=A_{k} x_{k}+B_{k} u_{k}+G_{k} w_{k}
$$

dengan pengukuran

$$
z_{k+1}=H_{k+1} x_{k+1}+v_{k}
$$

Dengan $x_{k}$ variabel keadaan berdimensi $n, u_{k}$ variabel input, $w_{k}$ noise model, $z_{k}$ data pengukuran atau output variabel, $v_{k}$ noise pada pengukuran, sedangkan $A_{k} ; B_{k} ; G_{k} ; H_{k}$ matriks matriks dengan ukuran bersesuaian.

Definisi 3.1 Misalkan $\phi(k, i)$ merupakan matriks transisi dari sistem (2) maka sistem dikatakan terobsevasi lengkap seragam atau terobsevasi secara statistik jika untuk setiap $N$ bulat terpenuhi

$$
\alpha_{0} I \leq \sum_{k=i}^{N-1} \phi^{T}(k, i) H_{k}^{T} R_{k}^{-1} H_{k} \phi(k, i) \leq \alpha_{1}
$$

untuk suatu $i<N ; \alpha_{0}>0 ; \alpha_{1}>0$

Definisi 3.2 Misalkan $\phi(k, i)$ merupakan matriks transisi dari sistem (2) maka sistem dikatakan tercapai lengkap seragam atau tercapai secara statistik jika untuk setiap $N$ bulat terpenuhi

$$
\alpha_{0} \leq \sum_{k=i}^{N-1} \phi^{T}(N, k+1) G_{k}^{T} Q_{k}^{-1} G_{k} \phi(N, k+1) \leq \alpha_{1}
$$

untuk suatu $i<N ; \alpha_{0}>0, \alpha_{1}>0$

Keterobservasian dan ketercapaian stokastik dengan $A_{k} ; Q_{k} ; R_{k}$ terbatas menjamin perilaku matriks kovariansi

$$
P_{k+1}^{-}=A_{k} P_{k} A_{k}^{T}+G_{k} Q_{k} G_{k}^{T}
$$


dan

$$
P_{k+1}=\left(I-K_{k} H_{k}\right) P_{k+1}^{-}
$$

yang tidak tergantung pada pemilihan kovariansi awal $P_{0}$ untuk $k$ cukup besar, serta sistem error Kalman Filter stabil asimptotik seragam [2].

Dengan $Q_{k}=0$, hubungan antara $P_{k}$ dan $P_{0}$ dapat dituliskan sebagai berikut :

$$
P_{k}=\phi_{, 0}\left[P_{0}^{-1}+\sum_{n=1}^{k} \phi_{k, 0}^{T} H_{n}^{T} R_{n}^{-1} H_{n} \phi_{k, 0}\right]^{-1} \phi_{k, 0}^{T}
$$

Variabel $x_{k}$ dapat ditentukan secara tunggal berdasarkan data pengukuran $z_{k}$ jika dan hanya jika matriks $\sum_{n=1}^{k} \phi_{k, 0}^{T} H_{n}^{T} R_{n}^{-1} H_{n} \phi_{k, 0}$ non singular.

Keterbatasan suatu matriks diperlukan pada saat menentukan keterbatasan matriks kovariansi.

\subsection{Keterbatasan Matriks $P_{k}$}

Disini akan ditunjukkan bahwa jika sistem terobservasi $m$-langkah pada interval $\left[t_{0}, t_{N}\right]$ untuk $N \in \mathbb{N}$ dengan $A_{k} ; H_{k} ; G_{k}$ berhingga maka sistem tersebut terobservasi lengkap seragam, artinya ada $m \in \mathbb{N}, \alpha>0$ dan $\beta>0$ sedemikian sehingga

$$
0<\alpha I \leq \sum_{j=k-m}^{k} \phi_{j, k-m-1}^{T} H_{j}^{T} R_{j}^{-1} H_{j} \phi_{j, k-m-1} \leq \beta I
$$

a. Misalkan $N \in \mathbb{N}$ yang cukup besar, $M_{k, k-m}$ definit positif berarti $\forall k \geq$ $m$, ada $\alpha_{k}>0$ sedemikian sehingga $0<\alpha_{k} I \leq M_{k, k-m}$. Misalkan $\alpha=\min \left\{\alpha_{k} \mid m \leq k \leq N\right\}$, maka

$$
0<\alpha \leq \sum_{j=k-m}^{k} \phi_{j, k-m-1}^{T} H_{j}^{T} R_{j}^{-1} H_{j} \phi_{j, k-m-1}
$$

untuk setiap $m \leq k \leq N$.

b. Jika matriks $A_{k}, H_{k}, G_{k}$ berhingga, maka

$$
M_{k, k-m}=\sum_{j=k-m}^{k} \sum \phi_{j, k-m-1}^{T} H_{j}^{T} R_{j}^{-1} H_{j} \phi_{j, k-m-1}
$$


berhingga. Misalkan untuk setiap $k \geq m$ berlaku $M_{k, k-m} \geq \lambda_{k} I$ dengan $\lambda_{k}$ adalah nilai eigen maksimum dari $M_{k, k-m}$, sehingga untuk $N \in \mathbb{N}$ cukup besar diperoleh barisan bilangan hingga $\lambda_{m}, \lambda_{m+1}, \lambda_{m+2}, \ldots, \lambda_{N}$. Untuk $j \geq N$ berlaku juga $M_{j, j-m} \leq \lambda_{j}$, dengan memilih $\beta=$ $\max \left(\lambda, \lambda_{j}\right)$ untuk setiap $j \geq N$ maka diperoleh $M_{k, k-m} \leq \beta I$ untuk setiap $k \geq m$.

Dari kedua penurunan diatas dapat disimpulkan bahwa sistem terobservasi $m$-langkah dengan matriks-matriks $A_{k}, H_{k}, G_{k}$ berhingga merupakan sistem terobservasi lengkap seragam pada interval $\left[t_{0}, t_{N}\right]$.

Selanjutnya, berdasarkan lemma invers matriks [5] dapat diturunkan batas atas dan batas bawah dari kovarian kesalahan estimasi $P_{k}[1]$ untuk sistem terobservasi $m$-langkah :

Batas Bawah $P_{k}$ yaitu

$$
P_{k} \geq \phi_{k, k-m}\left[P_{k-m}^{-1}+\sum_{j=k-m+1}^{k} \phi_{j, k-m}^{T} H_{j}^{T} R_{j}^{-1} H_{j} \phi_{j, k-m}\right]^{-1} \phi_{k, k-m}^{T}
$$

untuk $M_{k, k-m}=\sum_{j=k-m}^{k} \sum \phi_{j, k-m-1}^{T} H_{j}^{T} R_{j}^{-1} H_{j} \phi_{j, k-m-1}$ dan $M_{k, k-m} \geq$ $\lambda_{k} I$, maka

$$
P_{k} \geq \phi_{k, k-m}\left[P_{k-m}^{-1}+\beta I\right]^{-1} \phi_{k, k-m}^{T}
$$

Karena $\phi_{k, k-m}$ matriks berhingga maka $P_{k}$ terbatas dibawah jika $P_{k-m}$ definit positif.

Sedangkan batas atas $P_{k}$ adalah

$$
P_{k} \leq \phi_{k, k-m}\left[P_{k-m}+\sum_{j=k-m+1}^{k} \phi_{j, k-m}^{-1} G_{j-1} Q_{j-1} G_{j-1}^{T} \phi_{j, k-m}^{-T}\right] \phi_{k, k-m}^{T}
$$

atau

$$
P_{k} \leq \phi_{k, k-m} P_{k-m} \phi_{k, k-m}^{T}+\sum_{j=k-m}^{k} \phi_{k, k-j} G_{k-j+1} Q_{k-j+1} G_{k-j+1}^{T} \phi_{k, k-j}^{-T}
$$

Karena matriks-matriks $A_{k}, G_{k}$ berhingga mengakibatkan

$$
\sum_{j=k-m}^{k} \phi_{k, k-j} G_{k-j+1} Q_{k-j+1} G_{k-j+1}^{T} \phi_{k, k-j}^{-T}
$$


berhingga. Jadi $P_{k}$ terbatas diatas.

Dari pembahasan tersebut tampak bahwa matriks kovarian kesalahan estimasi $P_{k}$ terbatas pada interval waktu $\left[t_{0}, t_{N}\right]$ dengan $N$ cukup besar.

Pada masalah ini diperlukan pengertian tentang keterbatasan matriks, deret yang berhingga, dan norm. Konvergensi suatu matriks dipergunakan untuk mengetahui konvergensi matriks kovariansi.

\subsection{Konvergensi $P_{k}$}

Untuk menyelidiki konvergensi dari matriks kovariansi $P_{k}$ diturunkan suatu teorema sebagai berikut :

Teorema 3.3 Misalkan $P_{k}$ matriks kovarians kesalahan estimasi pada tahap koreksi. $P l_{k}$ batas bawah dari $P_{k}$. Jika $P l_{k}$ konvergen ke nol dan $P_{k}$ terbatas maka $P_{k}$ juga konvergen ke nol.

Bukti :

$$
\begin{aligned}
P_{k}^{-1} & =\left[A_{k-1} P_{k-1} A_{k-1}^{t}+G_{k-1} Q_{k-1} G_{k-1}^{t}\right]^{-1}+H_{k}^{t} R_{k} H_{k} \\
P l_{k}^{-1} & =\left[A_{k-1} P_{k-1} A_{k-1}^{t}\right]^{-1}+H_{k}^{t} R_{k} H_{k}
\end{aligned}
$$

maka

$\left\|P_{k}^{-1}-P l_{k}^{-1}\right\|=\left\|\left[A_{k-1} P_{k-1} A_{k-1}^{t}+G_{k-1} Q_{k-1} G_{k-1}^{t}\right]^{-1}-\left[A_{k-1} P_{k-1} A_{k-1}^{t}\right]^{-1}\right\|$

Misalkan $\sigma_{T}(i), \sigma_{l}(i)$ dan $\sigma_{Q}(i)$ masing-masing adalah nilai-nilai singular $A_{k-1} P_{k-1} A_{k-1}^{t}+G_{k-1} Q_{k-1} G_{k-1}^{t}, A_{k-1} P_{k-1} A_{k-1}^{t}$ dan $G_{k-1} Q_{k-1} G_{k-1}^{t}$ maka

$$
\begin{aligned}
\left|\frac{1}{\sigma_{T}(i)}-\frac{1}{\sigma_{l}(i)}\right| & =\frac{\left|\sigma_{l}(i)-\sigma_{T}(i)\right|}{\sigma_{T}(i) \sigma_{l}(i)} \leq \frac{\sigma_{Q}(i)}{\sigma_{T}(i) \sigma_{l}(i)} \\
& =\left\|G_{k-1} Q_{k-1} G_{k-1}^{t}\right\|
\end{aligned}
$$

sedangkan

$$
\begin{aligned}
\left\|P l_{k}-P_{k}\right\| & =\| P_{k}\left(P_{k}^{-1}-P l_{k}^{-1} P l_{k} \|\right. \\
& \leq\left\|P_{k}\right\|\left\|P_{k}^{-1}-P l_{k}^{-1}\right\|\left\|P l_{k}\right\|
\end{aligned}
$$

karena $\left\|P l_{k}\right\| \rightarrow 0$ untuk $k \rightarrow \infty,\left\|P_{k}\right\|$ terbatas dan $\left\|P_{k}^{-1}-P l_{k}^{-1}\right\|$ juga terbatas maka $\left\|P l_{k}-P_{k}\right\| \rightarrow 0$ untuk $k \rightarrow \infty$.

Disini nilai singular suatu matriks, keterbatasan matriks, pertidaksamaan dalam norm juga ikut berperan. 


\subsection{Filter Modifikasi RRSQRT}

Filter RRSQRT diajukan oleh Verlaan[6] untuk mengurangi waktu komputasi dari Filter Kovariansi Akar Kuadrat. Pada papernya telah ditunjukkan konvergensi dari algoritma tersebut. Filter modifikasi dari RRSQRT ini penulis ajukan untuk mengatasi noise sistem yang berupa vektor, bukan matriks seperti pada filter RRSQRT.

Pada RRSQRT filter, matriks kovariansi $P_{k}$ dinyatakan dalam $P_{k}=$ $L_{k}^{t} L_{k}$ dengan $L_{k}=\operatorname{chol}\left(P_{k}\right)$, dilakukan dekomposisi nilai singular $[U, D, V]=\operatorname{svd}\left(L_{k}^{t} L_{k}\right)$ dan selanjutnya melakukan reduksi rang dari $L_{k}^{*}=$ $\left[L_{k} U\right]_{1: n ; 1: q}$. Pada Modifikasi dari RRSQRT dilakukan dekomposisi nilai singular $\left[U_{1}, D_{1}, V_{1}\right]=\operatorname{svd}\left(L_{k+1}^{-}\right)$dan $L_{r}=\left[L_{k+1}^{-} V_{1}\right]_{1: n, 1: q}$ untuk menggantikan reduksi rank. Oleh karena itu perlu ditunjukkan bahwa hasil estimasi yang diperoleh adalah sama didasarkan pada teorema berikut:

Teorema 3.4 Jika $\left[U_{1}, D_{1}, V_{1}\right]=\operatorname{svd}\left(L_{k}^{-}\right)$maka $L_{r} L_{r}^{t}=L^{*}\left(L^{*}\right)^{t}$ dengan $L_{r}=\left[L_{k}^{-} V_{1}\right]_{1: n, 1: q}$ dan $L^{*}=\left[L_{k}^{-} U\right]_{1: n, 1: q}$ untuk $[U, D, V]=\operatorname{svd}\left(\left(L_{k}^{-}\right)^{t} L_{k}^{-}\right)$.

Bukti:

Misalkan $\left[U_{1}, D_{1}, V_{1}\right]=\operatorname{svd}\left(L_{k}^{-}\right)$, atau $D_{1}=U_{1}^{t} L_{k}^{-} V_{1}$ dengan $U_{1}, V_{1}$ masing-masing adalah matriks -matriks ortonormal dengan kolom-kolom berupa vektor singular kiri dan kanan dari $L_{k}^{-}$dan $D_{1}$ adalah matriks diagonal dengan elemen diagonal nilai singular $\lambda$ dari $L_{k}^{-}$, maka dapat dituliskan

$$
\begin{aligned}
D_{1}^{t} D_{1} & =\left(U_{1}^{t} L_{k}^{-} V_{1}\right)^{t}\left(U_{1}^{t} L_{k}^{-} V_{1}\right) \\
& =V_{1}^{t}\left(L_{k}^{-}\right)^{t} U_{1} U_{1}^{t} L_{k}^{-} V_{1} \\
& =V_{1}^{t}\left(L_{k}^{-}\right)^{t} L_{k}^{-} V_{1}
\end{aligned}
$$

dengan $D_{1}^{t} D_{1}$ adalah matriks diagonal dengan elemen diagonal kuadrat nilai singular $L_{k}^{-}, \lambda^{2}$, sedangkan $V_{1}$ adalah matriks ortonormal dengan kolom-kolom berupa vektor singular dari $L_{k}^{-}$. Golub [4] menyatakan bahwa vektor singular kanan, $V_{1}$ dari $L_{k}^{-}$dan vektor singular kiri, $U$ dari $\left(L_{k}^{-}\right)^{t} L_{k}^{-}$ adalah sama.

Dengan mendefinisikan $L_{r}=\left[L_{k}^{-} V_{1}\right]_{1: n, 1: q}$ dan $L^{*}=\left[L_{k}^{-} U\right]_{1: n, 1: q}$ akan diperoleh $L_{r} L_{r}^{t}=\left(L^{*}\right)\left(L^{*}\right)^{t}$. 
Tampak bahwa pada pembentukan modifikasi filter RRSQRT harus dipahami tentang vektor singular, nilai singular yang berkaitan dengan teori spektral, serta sifat ortogonal dan ortonormal dari vektor singular

\section{Penutup}

Dari uraian diatas tampak bahwa kemampuan analisis bagi seorang matematikawan sangat diperlukan agar dapat mengembangkan suatu algoritma maupun metode-metode bidang terapan. Tanpa kemampuan analisis kita akan menjadi pemakai algoritma, software ataupun metode-metode tanpa dapat mengembangkan, mengurangi waktu komputasi dan memperbaiki hasil estimasi.

\section{Pustaka}

[1] Apriliani, E. Reduksi Rang pada Filter Informasi Akar Kuadrat dan Modifikasi Filter Kovariansi Akar Kuadrat Rang Tereduksi untuk Sistem Berderau Vektor, Disertasi, 2002.

[2] Lewis, F.L., Optimal Estimation, John Wiley and Sons, 1986

[3] Le Dimet FX, Shutyaev,VP., Wang J and Mu MU, The Problem of data Assimilation for Soil Water Movement, ESAIM: Control Optimisation and Calculus Variation, Vol. 10, pp. 331-345, 2004

[4] Golub, G.H. and Van Loan,C.F., Matrix Computations, The Johns Hopkins University Press, London, 1989.

[5] Sorenson, Controllability and Observability of Linear Stochastic TimeDiscrete Control System, Advances in Control System, Vol. 6. , 1968.

[6] Verlaan, M. Ecient Kalman Filtering Algorithms for Hydrodynamic Models, PhD Thesis, TU Delft,1998 